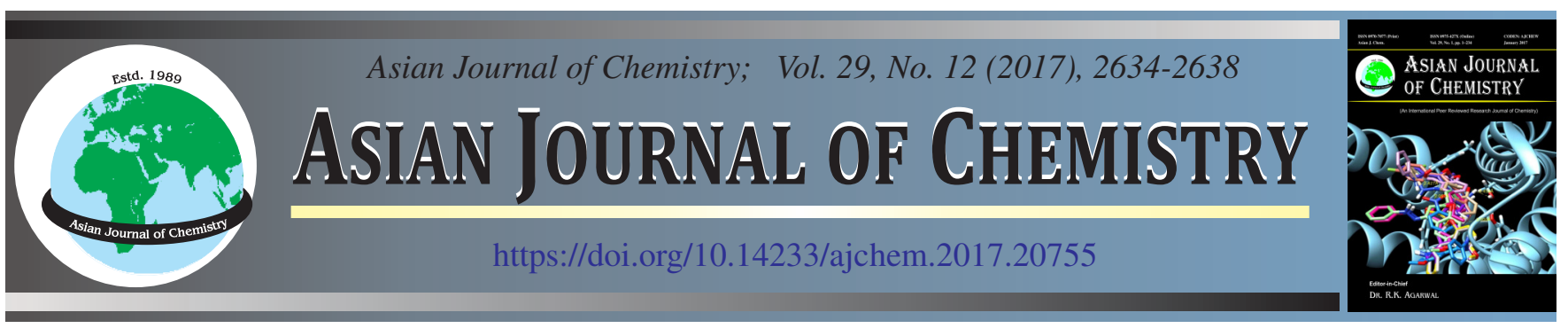

\title{
Synthesis and Characterization of Biomimetic Hydroxy Apatite-Silver Impregnated Soy Protein Isolate Nanocomposites for Dental Implantations
}

\author{
T. KRISHNAVEni ${ }^{1,2, *}$ and Alagunambi Ramasubbu ${ }^{1}$
}

${ }^{1}$ Post Graduate and Research Department of Chemistry, Government Arts College (Autonomous), Coimbatore-641 018, India ${ }^{2}$ Department of Chemistry, Misrimal Navajee Munoth Jain Engineering College, Chennai-600 097, India

*Corresponding author: E-mail: tveni2009@gmail.com

Received: 4 May 2017;

Accepted: 11 June 2017;

Published online: 30 October 2017;

AJC-18605

\begin{abstract}
A novel class of biomimetic hydroxyapatite (HAP), poly(vinyl alcohol) (PVA) and silver nanoparticles (AgNPs) impregnated soy protein isolate (SPI)-ternary and quaternary nanocomposites were fabricated by an environmentally benign hydrothermal precipitation process under UV irradiation. Various physico-chemical and mechanical characteristics showed improved mechanical properties that open up newer vistas in biomedical applications, especially for dental implantations and repairs. The SEM, FT-IR, powder-XRD, particle size distribution analysis, TG-DTA, and DSC results confirmed the complete miscibility of soy protein isolate, hydroxyapatite and poly(vinyl alcohol) through one another by strong hydrogen bonding and silver nanoparticles were evenly distributed into nano-matrix and are stable without any aggregation. The mechanical properties (tensile strength), water absorption test and in vitro antibacterial studies confirmed that soy protein isolate based composites have enough mechanical stability, low water absorption and low bacterial adhesion. The incorporation of poly(vinyl alcohol) as neutral fillers boosts the tensile strength. The TG-DTA and DSC studies envisaged better miscibility and morphological changes of hydroxyapatite, poly(vinyl alcohol) and silver nanoparticles impregnated soy protein isolate with one another with an induced thermal stability. This novel class of SPI/HAP/PVA/Ag nanocomposites shall be a potential alternative class of materials for teeth and bone, orthopaedic dental implant due to their chemical and biological similarity to human hard tissues.
\end{abstract}

Keywords: Nano-hydroxyapatite, Poly(vinyl alcohol), Soy protein isolate, Silver nanoparticles, Nanocomposites.

\section{INTRODUCTION}

Soy protein isolate (SPI) is the plant protein which contains 18 amino acids and polar functional groups like hydroxyl, amino and carbonyl groups. The popularity of soy protein has been increasing, mainly because of its health benefits [1] It has been proven that soy protein can help to reduce the proliferation of cancer cells [2-6]. The recent trends in implantology point a great applications of composite material based on biocompatible and biodegradable polymers. In past few years, soy protein isolate is used as a substitute for nonbiodegradable plastics in the food and packaging industry especially for its biocompatibility, film forming properties and oxygen barrier abilities [7]. However, hydrophilicity and very low mechanical properties of soy protein isolate decreases its usage mainly in biomedical field [8]. Denaturation can be induced by varying its $\mathrm{pH}$ away from its isoelectric point $(\mathrm{pH}$ 4.5) makes the protein to unfold and increases its dispersion in water [9]. This will also increase the mechanical properties by exposing hydrophobic groups and reformation of disulphide bond, forming a new structural compound through strong hydrogen bonding [10]. In the present study, soy protein isolate (SPI) was mixed with hydroxyapatite (HAP), the most extensively used mineral in the biomedical field due to its excellent osteoconductive and osteointegration property, resorbability possesses structural similarity to bone mineral and has the ability to bond directly with bone/dentine [11]. Soy protein isolate based hydroxyappatite can be used as a dental filling material or as a reinforcing material. In order to increase the mechanical property and reduce the moisture absorption of SPI/HAP, the synthetic biodegradable, thermal stable polymer called poly(vinyl alcohol) is incorporated [12]. Bacterial adhesion is associated with the formation of biofilm or growth of bacterial cells on the artificial surfaces that has been introduced into the human body, manifest high resistance against antibacterial substances leads to localized destruction of implant structures. In order to prevent the bacterial infections, the synthesized composite SPI/HAP/ PVA was incorporated with silver nanoparticles in the presence of UV radiation. Silver based antibacterial agents play an important role in the biomedical field for a long time. It is evident from several studies that use of $\mathrm{Ag}^{+}$reduces the extent of bacterial infection on the implant surfaces [13-16]. Therefore, the silver 
impregnated SPI/HAP/PVA is an interesting alternative, used as structural material or reinforcing elements for orthodontic applications.

\section{EXPERIMENTAL}

The solution of soy protein isolate $(5 \%)$ was obtained by dissolving $5 \mathrm{~g}$ of soy protein isolate powder in $100 \mathrm{~mL}$ of deionized water. $1.0 \mathrm{~mol} / \mathrm{L} \mathrm{NaOH}$ was added in SPI solution with continuous stirring rate of $250 \mathrm{rpm}$ for $1 \mathrm{~h}$. The $\mathrm{pH}$ was adjusted to 9-10 to make the protein unfold and to form new structural arrangements with other components. The solution of $\mathrm{CaNO}_{3} \cdot 4 \mathrm{H}_{2} \mathrm{O}$ $(1 \mathrm{M})$ was prepared and approximate amount of $\mathrm{AgNO}_{3}(1 \mathrm{~g}$ and $1.6 \mathrm{~g})$ was added. The mixture was placed in a closed cuvette and irradiated with UV light $(254 \mathrm{~nm}, 40 \mathrm{~W})$ under mild stirring at room temperature for $12 \mathrm{~h}$. Poly(vinyl alcohol) solution (5\%) was prepared in a hot plate with magnetic stirrer at $60^{\circ} \mathrm{C}$ for $1 \mathrm{~h}$. Then the prepared 5\% SPI solution, 5\% PVA solution and $0.6 \mathrm{M}$ potassium dihydrogen phosphate solution were added to silver doped $\mathrm{CaNO}_{3} \cdot 4 \mathrm{H}_{2} \mathrm{O}$ mixture. Once the addition was completed, the composite mixture was stirred at the rate of $200 \mathrm{rpm}$ for $6 \mathrm{~h}$. The resultant white precipitate was filtered, washed and dried at $70{ }^{\circ} \mathrm{C}$ for $24 \mathrm{~h}$. Thus obtained films were kept in the desiccators for 5 days for the complete evaporation of solvent. The composite without PVA was also prepared in the same way to determine the mechanical stability of quaternary nanocomposite. The samples with the weight ratios of with $5 \%$ and without PVA containing SPI/HAP/Ag composite with $1 \mathrm{~g}$ AgNPs and $1.6 \mathrm{~g}$ AgNPs were characterized.

The morphology of biocompatible nanocomposite films were visualized using FEI Quanta FEG 200 High Resolution Scanning Electron Microscope equipped with EDAX working at accelerating voltage of $5 \mathrm{KV}$, Magnification (12000X to $1,00,000 \mathrm{X})$. FT-IR spectra of prepared samples were analyzed using Nicollet Imact 400 using KBr pellets. XRD patterns were recorded using Bruker, D8 Advance PXRD Instrument with a single gobel mirror. The samples were scanned from $10^{\circ}$ to $80^{\circ} \mathrm{C}$, $2 \theta$ at a scan rate of $0.05 / \mathrm{min}$. The average particle size of nanocomposite was measured by Malvern particle size analyzer (Mastersizer 2000, Malvern Instruments). The thermal stability of synthesized composites with $5 \%$ and without PVA were examined with Perkin Elmer Q500 Hi-Res TGA over a temperature range of $30{ }^{\circ} \mathrm{C}$ to $900{ }^{\circ} \mathrm{C}$ at a heating rate of $20{ }^{\circ} \mathrm{C} / \mathrm{min}$ under nitrogen atmosphere. The DSC patterns of the prepared samples were obtained using DSC Q 200V 24.4. The heating rate of $1 \mathrm{~K} / \mathrm{min}$ and the temperature range between $-80^{\circ} \mathrm{C}$ and $145^{\circ} \mathrm{C}$ under nitrogen atmosphere. The mechanical property, tensile strength was determined with a universal testing machine (INSTRON model 1405). Water permeability test was carried out by ASTM D570-81. The synthesized composites were dried under vacuum and immersed in deionized water for two days at $25^{\circ} \mathrm{C}$. The weight gain in percentage was taken as water permeability value. The values taken are averages of 3 specimens. In vitro antimicrobial studies were performed against five different microorganisms namely Staphylococcus aureus, Escherichia coli, Bacillus subtilis, Enterooccus faecalis and Pseudomonas aeruginosa by well diffusion method. The selected pathogenic strains were obtained from Microbiological Division (Jayagen Biologics Analytical Laboratory, Chennai, India).

\section{RESULTS AND DISCUSSION}

Surface morphology of nanocomposite before and after adding PVA was studied using scanning electron microscope technique. Fig. 1(a) and 1(b) shows the images of SPI nanocomposite with $5 \%$ and without PVA. The addition of biodegradable PVA results in changes in the morphology of the composite. Surface of the ternary nanocomposite (without PVA) was distinctly corrugated than quaternary nanocomposite which contains $5 \%$ PVA. Fig. 1(c) presents EDAX spectrum and linear scan of prepared composite. It was observed that particles of HAP, PVA and silver were well-uniformly distributed and forms a bonding with biopolymer SPI. Moreover, AgNPs were monodispersed with minimum agglomerations on the protein surface. EDAX spectrum confirmed peaks corresponded to polymer matrix, hydroxyappatite $\mathrm{Ca}$ and $\mathrm{P}$ as well as $\mathrm{Ag}$ ion.

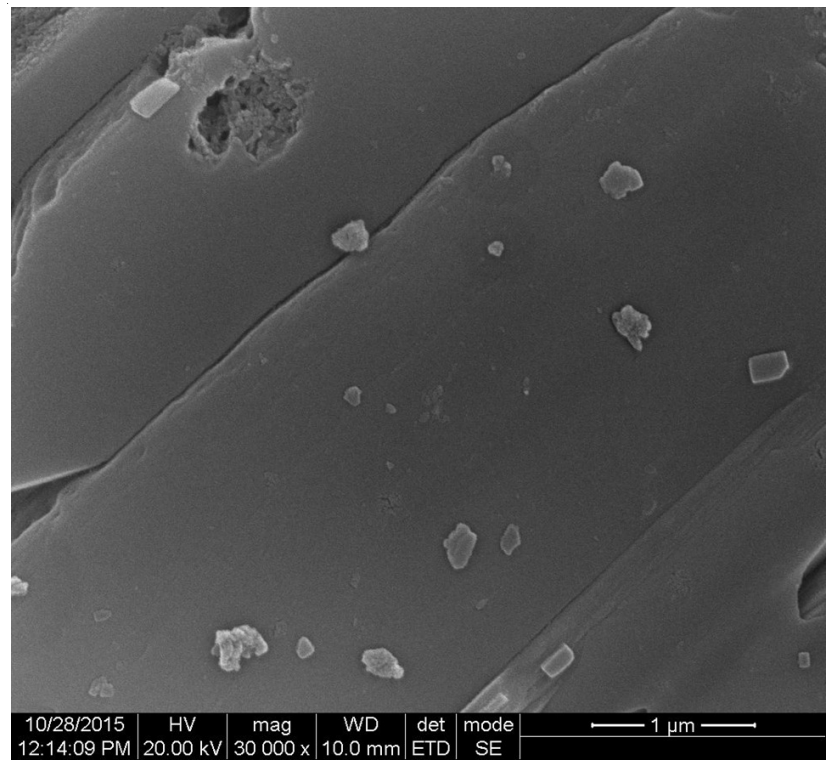

Fig. 1(a). HR-SEM of SPI/HAP/PVA/Ag quaternary nanocomposite under the magnification of $30000 \mathrm{X}$

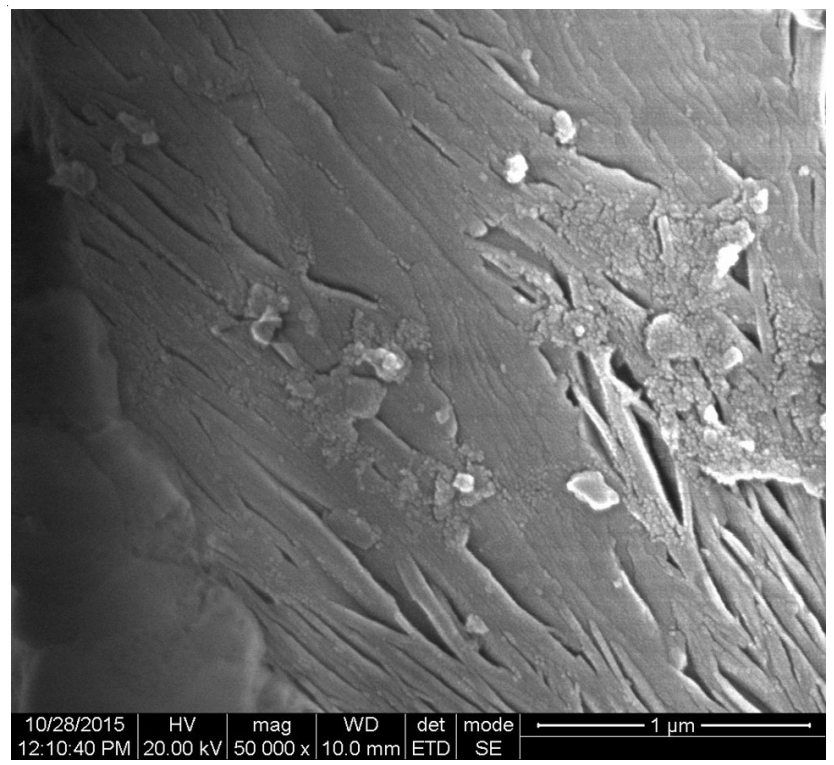

Fig. 1(b). HR-SEM of SPI/HAP/Ag ternary nanocomposite under the magnification of $50000 \mathrm{X}$ 


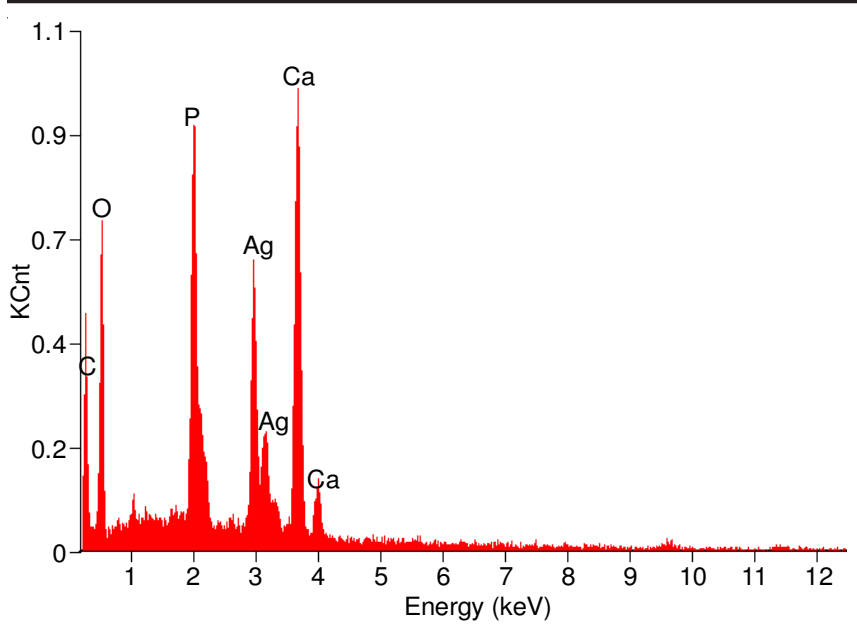

Fig. 1(c). EDAX spectrum of SPI/HAP/PVA/Ag quaternary nanocomposite

Fig. 2(a) shows the FT-IR spectra of synthesized nanocomposite demonstrate the vibration characteristics of functional groups present on neat HAP, SPI and PVA. The peak at 3541 $\mathrm{cm}^{-1}$ corresponded to $\mathrm{OH}^{-}$stretching mode and the band from $1384,1650 \mathrm{~cm}^{-1}$ show the CO stretching of carbonate group in HAP. The peak was observed in the range 1064 and 1132 $\mathrm{cm}^{-1}$ corresponds to $\gamma_{3}$ asymmetric stretching of PO bond of phosphate group in HAP. The addition of $\mathrm{Ag}$ into HAP shows the changes in the absorption bands of $\mathrm{PO}_{4}{ }^{3-}$ and $\mathrm{OH}^{-}$(i.e.) the vibration modes of $\mathrm{OH}^{-}$intensity is decreased at $659 \mathrm{~cm}^{-1}$ while and $3488 \mathrm{~cm}^{-1}$ is due to broadening of $\mathrm{PO}_{4}{ }^{3-}$ bands as compared to HAP. Thus the addition of silver affected on HAP crystalline nature. The addition of SPI shows its characteristic peaks of combined stretching of $\mathrm{NH}$ and $\mathrm{OH}$ at $3282 \mathrm{~cm}^{-1}$. The peaks around 1650,1542 and $1384 \mathrm{~cm}^{-1}$ shows the characteristic bands of amide: amide $\mathrm{I}(\mathrm{C}=\mathrm{O}$ stretching) and amide II and amide III (N-H stretching and $\mathrm{CN}$ stretching), respectively. The peaks around 3488, 2394 and $1064 \mathrm{~cm}^{-1}$ represent the corresponding $\mathrm{OH}$ stretching, asymmetric stretching of $\mathrm{CH}_{2}$ and stretching of $\mathrm{CO}$ from crystalline sequence of PVA. It is worth to note that there was difference between pure SPI, HAP, PVA and the composite SPI/HAP/PVA/Ag with the increasing SPI content in the nanocomposite, the relative intensities of combined stretching of $\mathrm{NH}$ and $\mathrm{OH}$ at $3300 \mathrm{~cm}^{-1}$ of neat SPI and peak at $3571 \mathrm{~cm}^{-1}$ of $\mathrm{OH}^{-}$group in neat HAP becomes disappeared and shifted to low wavenumber $3282 \mathrm{~cm}^{-1}$. Also a

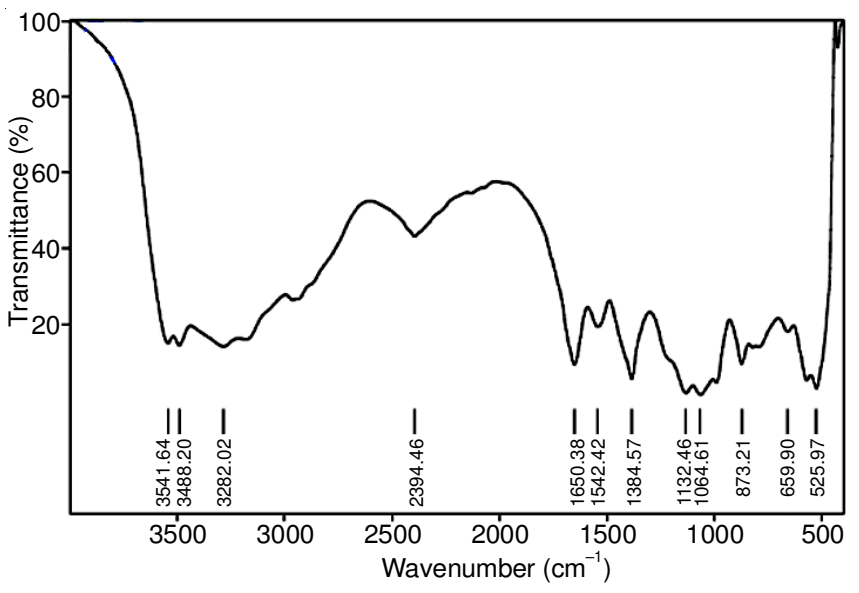

Fig. 2(a). FT-IR spectra of SPI/HAP/PVA/Ag quaternary nanocomposite strong single absorption band appears at $2394 \mathrm{~cm}^{-1}$. The above changes elucidate the interaction between the biopolymer SPI, HAP and PVA through strong hydrogen bonding.

$\mathrm{X}$-ray diffraction powder pattern of quaternary nanocomposite (Fig. 2b) shows a low intensity peak at $2 \theta$ value of about $21.20^{\circ}$ as compared with those of neat PVA, SPI, HAP and ternary nanocomposite. This shows that the crystalline nature of SPI, PVA or HAP has destroyed after nanocompositing. The decrease in intensity is also due to the presence of $\mathrm{OH}^{-}$ group of PVA, causes the steric entrapment of $\mathrm{Ca}^{2+}$ ions of HAP [17]. Furthermore, according to Debye-Scherer's equation I = $0.9 \lambda / \beta \cos \theta$, the size range of SPI quaternary nanocomposite was found from $14 \mathrm{~nm}$ to $90 \mathrm{~nm}$ in diameter. More than that particle size distribution analysis (Fig. 2c) shows $90 \%$ of particles were in the size less than $30 \mathrm{~nm}$, indicating the dispersed Ag nanopar-ticles in SPI composite were highly stable and showed no signs of aggregation.

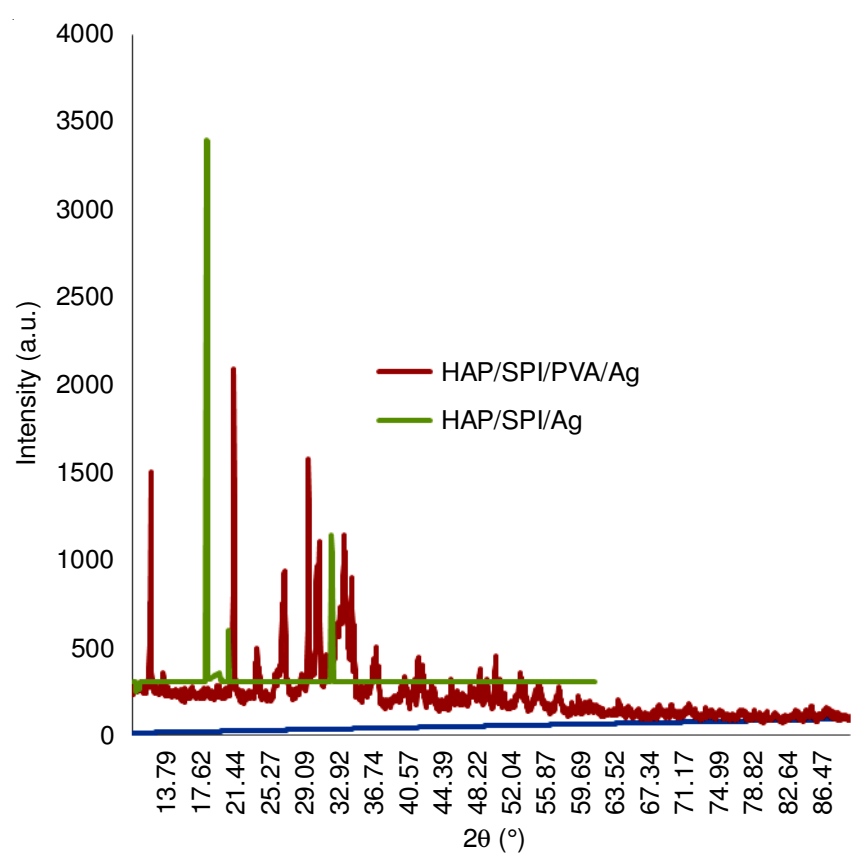

Fig. 2(b). Powder-XRD pattern of SPI/HAP/PVA/Ag quaternary and SPI/ HAP/Ag ternary nanocomposite

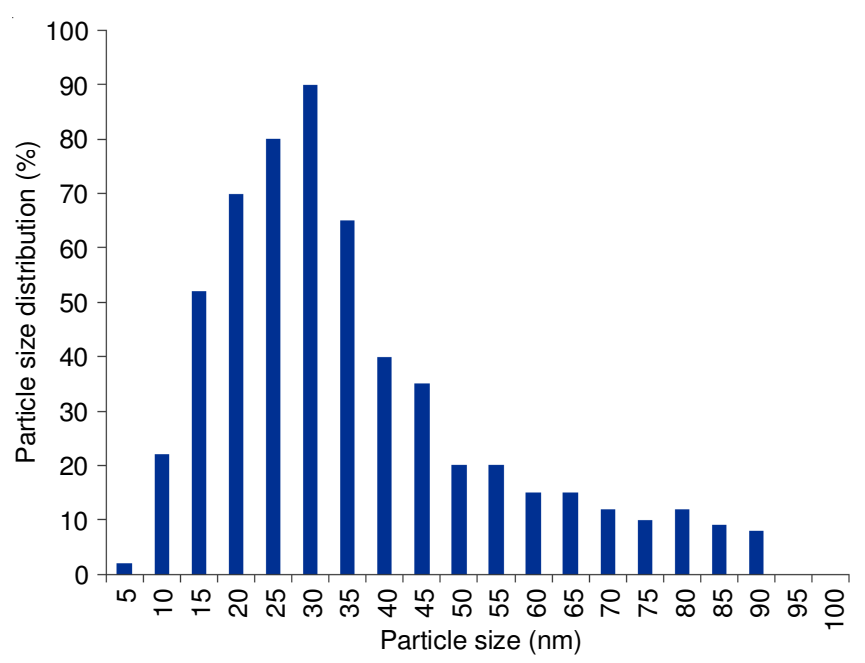

Fig. 2(c). Particle size distribution of SPI/HAP/PVA/Ag quaternary nanocomposite 
Fig. 3a shows the TGA curve of the quaternary nanocomposite gives information relevant to heat stability by measuring weight loss from thermal degradation as a function of temperature. First order derivative of TGA revealed the temperature at which the maximum decrease of mass occur. The maximum loss rate of quaternary nanocomposite occurs at the temperature range of $310^{\circ} \mathrm{C}$ to $450^{\circ} \mathrm{C}$. This clearly showed that the side chain of PVA readily decomposed before the decomposition of the main chain of PVA. After $500^{\circ} \mathrm{C}$, the composite exhibited a significant delay in weight loss.

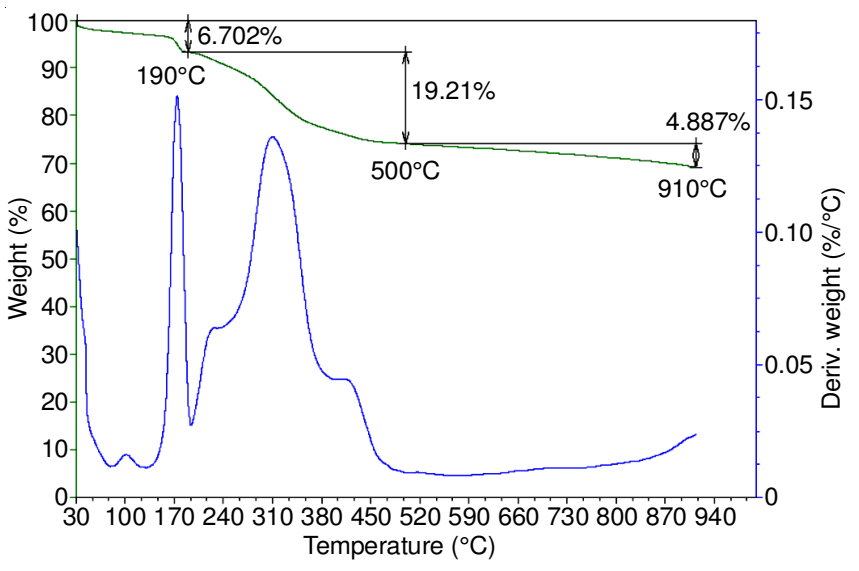

Fig. 3(a). TGA curve of SPI/HAP/PVA/Ag quaternary nanocomposite

Fig. 3b shows the DSC curve of quaternary nanocomposite elucidate the information about changes in the polymer state or polymer stability by changes in the heat capacity of the material as the temperature increases or decreases at a constant rate. $\mathrm{T}_{\mathrm{g}}$ thus obtained in the curve is observed to be in the range of from 130 to $140{ }^{\circ} \mathrm{C}$ which is higher than that of neat HAP, PVA, SPI and ternary nanocomposite SPI/HAP/Ag. This is due to the complete miscibility and the formation of intermolecular hydrogen bonding by destroying the crystalline structures of HAP, PVA and SPI [18]. In addition, single $T_{g}$ in curve revealed the good biocompatibility of the nanocomposite and renders itself as a suitable biomaterial for orthodontal applications. Overall, these properties reduce the perfection of crystalline structure by increasing the degree of cross-linking, thereby increases the stability of quaternary nanocomposite SPI/HAP/ PVA/Ag.

Low mechanical property and high moisture conductivity are the two main inherent problems of using soy protein isolate doped polymer composites. To overcome this, the mechanical property of the nanocomposite was increased by the addition of secondary biocompatible polymer poly(vinyl alcohol). The prepared quaternary nanocomposite SPI/HAP/PVA/Ag showed a tensile strength upto $42.8 \mathrm{Mpa}$ than the ternary nanocomposite, neat HAP, neat SPI and neat PVA. It was found that the presence of additional or secondary component PVA improves the mechanical strength and elasticity of SPI nanocomposite. This enhancement in mechanical property is also due to the presence of interaction between HAP, SPI and PVA molecules through strong hydrogen bonding. The hydroxyl group of HAP and PVA and the carbonyl group in amino acid residues and peptides of proteins form hydrogen bonding interaction between the polymer, ceramic and $\mathrm{Ag}$ metal ion.

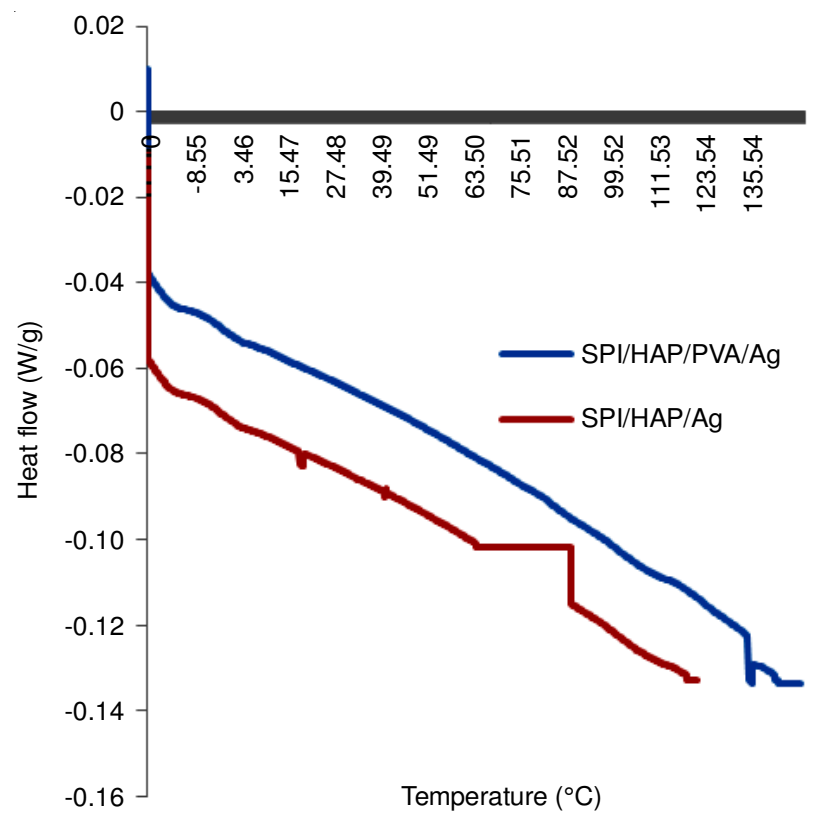

Fig. 3(b). DSC curve of SPI/HAP/PVA/Ag quaternary nanocomposite

Water absorption values of quaternary nanocomposite films decreases in an obvious manner compared with the ternary nanocomposite, neat HAP, SPI and PVA. Though they were hydrophilic in nature, the water barrier properties of quaternary nanocomposite were increased due to the formation of intermolecular interaction between HAP, SPI and PVA through strong hydrogen bonding. This was also the reason for the enhancement of the mechanical properties of quaternary nanocomposite films than that of neat HAP, SPI and PVA.

Bacterial adhesion is associated with the formation of biofilm or growth of bacterial cells on the artificial surfaces that has been introduced into the human body, manifest high resistance against antibacterial substances, leads to localized destruction of implant structures. In order to prevent bacterial adhesion and colonization, the antibacterial studies are carried out. The diameter of inhibiting zones was found to vary from 10 to $24 \mathrm{~mm}$ in SPI/HAP/PVA/Ag quaternary nanocomposite (Table-1), which shows an excellent antibacterial activity against the selected bacterial strains. This is mainly due to the presence of $\mathrm{Ag}^{+}$ion in SPI/HAP/PVA ternary nanocomposite which prevents the adhesion of any kind of microorganisms.

TABLE-1

ANTIBACTERIAL ACTIVITY BY

THE WELL DIFFUSION METHOD

\begin{tabular}{lccc}
\hline \multirow{2}{*}{$\begin{array}{c}\text { Name of the } \\
\text { organisms }\end{array}$} & \multicolumn{3}{c}{ Concentration at 200 $\mu \mathrm{g} /$ well } \\
\cline { 2 - 4 } & SPI/HAP/PVA/Ag* & SPI/HAP/PVA* & SPI/HAP* \\
\hline B. subtilis & 15 & 15 & 9 \\
E. faecalis & 23 & 18 & 6 \\
S. aureus & 24 & 11 & 9 \\
E. coli & 16 & 10 & 7 \\
P. aeruginosa & 10 & 13 & 10 \\
\hline *ZOI = Zone of inhibition $(\mathrm{mm})$ & &
\end{tabular}

\section{Conclusion}

In conclusion, a novel class of biomimetic SPI/HAP/PVA/Ag quaternary and SPI/HAP/PVA ternary nanocomposites were 
successfully prepared and characterized by an environmentally benign hydrothermal precipitation process under UV irradiation. SEM, FTIR and XRD patterns clearly shows that the obtained quaternary nanocomposite SPI/HAP/PVA/Ag films are amorphous and the intermolecular interaction between HAP, SPI and PVA mainly occurred by strong hydrogen bonding. The tensile property and morphology of the quaternary nanocomposites changed with increasing the biodegradable polymer PVA, which acts as a stabilizer as well as a compatibilizer. The TGA and DSC studies predicted the good miscibility, morphological fundamental changes and the thermal stability of obtained quaternary nanocomposite. in vitro Antibacterial activity strongly demonstrated that the synthesised quaternary nanocomposites have shown improved antibacterial activity against five different bacterial strains and can be used in orthodontic applications. Overall, addition of poly(vinyl alcohol) has improved the morphological characteristics, mechanical strength and water resistant ability of SPI/HAP/Ag ternary nanocomposites. Towards this, the intrinsic bioactivities of soybean were successfully exploited in developing a greener nanocomposite with improved mechanical properties that open up newer vistas in biomedical applications, especially for orthopaedic repairs, orthopaedic fillers and dental restorations.

\section{ACKNOWLEDGEMENTS}

One of the authors (A.R.) thankfully acknowledges UGC, New Delhi, for financial assistant in the form of Major Research Project (File No.: 39-723/2010 (SR); Dated 11/01/2011).

\section{REFERENCES}

1. R.-L. Wu, X.-L. Wang, Y.-Z. Wang, X.-C. Bian and F. Li, Ind. Eng. Chem. Res., 48, 7132 (2009);

https://doi.org/10.1021/ie9001052.

2. A. El-Ghannam, Expert Rev. Med. Devices, 2, 87 (2005); https://doi.org/10.1586/17434440.2.1.87.
3. E.J. Acosta, Inform-Int. News on Fats, Oils and Related Materials, 18, 56 (2007).

4. M. Santin and L. Ambrosio, Expert Rev. Med. Devices, 5, 349 (2008); https://doi.org/10.1586/17434440.5.3.349.

5. N.A. Deak, P.A. Murphy and L.A. Johnson, J. Am. Oil Chem. Soc., 84, 137 (2007); https://doi.org/10.1007/s11746-006-1017-1.

6. F. Perut, E.B. Montufar, G. Ciapetti, M. Santin, J. Salvage, T. Traykova, J.A. Planell, M.P. Ginebra and N. Baldini, Acta Biomater., 7, 1780 (2011); https://doi.org/10.1016/j.actbio.2010.12.012.

7. J.-F. Su, Z. Huang, C.-M. Yang and X.-Y. Yuan, J. Appl. Polym. Sci., 110, 3706 (2008);

https://doi.org/10.1002/app.28979.

8. A.H. Brandenburg, C.L. Weller and R.F. Testin, J. Food Sci., 58, 1086 (1993); https://doi.org/10.1111/j.1365-2621.1993.tb06120.x.

9. R. Kumar, V. Choudhary, S. Mishra, I.K. Varma and B. Mattiason, Ind. Crops Prod., 16, 155 (2002); https://doi.org/10.1016/S0926-6690(02)00007-9.

10. P. Nayak, S.K. Sahoo, A. Behera, P.K. Nanda, P.L. Nayak and B.C. Guru, World J. Nano Sci. Engg., 1, 27 (2011); https://doi.org/10.4236/wjnse.2011.12005.

11. J.J. Keegan, G. Patel and H. Rubin, Anhydrous Products having Improved Wettability Characteristics, US Patent, 3,919,138 (1975).

12. I. Vroman and L. Tighzert, Materials, 2, 307 (2009); https://doi.org/10.3390/ma2020307.

13. L. Ge, Q. Li and M. Wang, Int. J. Nanomed., 9, 2399 (2014).

14. A.M. Atta, H.A. Al-Lohedan and A. Ezzat, Molecules, 19, 6737 (2014); https://doi.org/10.3390/molecules 19056737.

15. C.S. Clobanu, S.L. Iconaru, M.C. Chifiriuc, A. Costescu, P. Le Coustumer and D. Predoi, Biomed. Res. Int., Article ID 916218 (2013); https://doi.org/10.1155/2013/916218.

16. Z. Shi, K.G. Neoh, E.T. Kang and W. Wang, Biomaterials, 27, 2440 (2006); https://doi.org/10.1016/j.biomaterials.2005.11.036.

17. A. Sobczak-Kupiec, D. Malina, M. Piatkowski, K. Krupauczek, Z. Wzorek and B. Tyliszczak, J. Nanosci. Nanotechnol., 12, 9302 (2012); https://doi.org/10.1166/jnn.2012.6756.

18. D.A. Cardoso, J.A. Jansen and S.C.G. Leeuwenburgh, J. Biomed. Mater. Res., 100B, 2316 (2012); https://doi.org/10.1002/jbm.b.32794. 